\title{
Biodiesel from Oilseeds in the Canadian Prairies and Supply-Chain Models for Exploring Production Cost Scenarios: A Review
}

\author{
Nathaniel K. Newlands ${ }^{1}$ and Lawrence Townley-Smith ${ }^{2}$ \\ ${ }^{1}$ Environmental Health, Agriculture and Agri-Food Canada, Lethbridge Research Centre, P.O. Box 3000, Lethbridge, \\ $A B$, Canada T1J $4 B 1$ \\ ${ }^{2}$ Agri-Environmental Service Branch (AESB), Agriculture and Agri-Food Canada, 1800 Hamilton Street, Regina, \\ SK, Canada S4P 4L2 \\ Correspondence should be addressed to Nathaniel K. Newlands, nathaniel.newlands@agr.gc.ca
}

Received 14 February 2012; Accepted 13 March 2012

Academic Editors: O. Ferrarese-Filho, J. Hatfield, and B. Kindiger

Copyright ( 2012 N. K. Newlands and L. Townley-Smith. This is an open access article distributed under the Creative Commons Attribution License, which permits unrestricted use, distribution, and reproduction in any medium, provided the original work is properly cited.

\begin{abstract}
Canada recently implemented a federal mandate of $2 \%$ of renewable content in diesel fuel and heating oil. Federal-level biofuel strategy is currently more geared to bioethanol, as nonfood oils continue to be more cost-competitive and canola seeded area is forecast to increase $10 \%$ as a new record due to strong prices and high expected yields. Increasing focus is therefore being placed on alternative oilseeds as nonfood crops for biodiesel and their ability to adapt to the semiarid conditions of the Canadian Prairies and provide benefits in nutrient and water-use efficiency when introduced into the crop rotation. Systems engineering and supply-chain modeling and optimization will have an increasingly important role in decision making for designating supply units, the linkage of processes and chains, and biorefinery system design. However, current models require further enhancement to address current challenging questions: (1) changing spatial considerations (e.g., land use and suitability for feedstocks), (2) changing temporal dynamics of supply and risk of climate extreme impacts on transportation networks (road, rail, pipeline), price volatility, changes in policy targets and subsidy regimes, process technological change, and multigenerational biorefinery systems engineering advancements. Greater integration internationally in model development and testing would improve sensitivity and reliability in their system-level predictions and forecasts.
\end{abstract}

\section{Introduction}

Biofuel is fuel that is derived from biomass or living organisms and/or their metabolic byproducts. It is termed renewable (unlike fossil fuel (petroleum, coal) and nuclear energy sources) because it produces electrical, thermal, and/or mechanical energy at rates that are faster than the rate at which its resource base is consumed. Canada's annual primary energy supply is roughly 11 exajoules of which roughly $17 \%$ is renewable (i.e., $11 \%$ from hydroelectricity and 6\% from biomass) [1]. Nonetheless, renewable bioenergy supplied from agricultural reigons and forest wastes (with contributions from industrial, municipal solid waste, and sewage biogas), energy crops, wind, and solar sources continues to increase. Currently, the pulp and paper and forest-product industries recycle half of their total energy use by converting bioenergy into electricity, steam, and heat, while fuelwood and gas from landfills are used in heating residential spaces. Bioenergy is currently transformed into biofuel for generating power as urban and rural electricity, heating water and spaces, and transportation.

Biofuel production, to be a viable renewable source of energy supply, must provide a net energy gain, have environmental benefits, be economically competitive, and be producible in large quantities, without reducing food supplies [2]. The use of biofuel in Canada's transportation is of special interest given that this sector contributes about $28 \%$ of national carbon dioxide $\left(\mathrm{CO}_{2}\right)$ emissions, in addition to reducing environmental air quality [3]. Here, displacing fossil fuel with biofuel would reduce net emissions of carbon 
into the atmosphere and would help to mitigate environmental impacts of increased atmospheric greenhouse gases (GHGs). The agricultural sector also has a direct role in some of the newly implemented biobased energy systems because farm products are the primary input into many of these systems, including grains (ethanol), oilseeds (biodiesel), waste products (biogas), cellulosic materials (ethanol), and woody biomass (heat energy, biogas). In 2011, Canada implemented a federal mandate of $2 \%$ of renewable content in diesel fuel and heating oil that sets a target of $600 \mathrm{MLyr}^{-1}$ of domestic production from current 2011 levels forecasted at $158 \mathrm{ML} \mathrm{yr}^{-1}$ (that have attained a $13 \%$ increase from 2010 levels of $140 \mathrm{ML} \mathrm{yr}^{-1}$ or $0.1 \mathrm{GL} \mathrm{yr}^{-1}$ ). This compares to current biodiesel production of $6.1 \mathrm{GL} \mathrm{yr}^{-1}$ in the European Union and $1.9 \mathrm{GL} \mathrm{yr}^{-1}$ (505 mgy) in the United States. In the U.S. there are 191 biodiesel operating facilities having a capacity of $10.6 \mathrm{GL} \mathrm{yr}^{-1}$ (i.e., 2.8 billion gallons $\mathrm{yr}^{-1}$ (bgy), US EPA, 2010). A biorefinery in Saskatchewan (Canada Bioenergy/ADM plant situated in Lloydminster) is currently under construction and is anticipated to raise Canada's biodiesel production capacity by $225 \mathrm{ML}$ to a total of $475 \mathrm{ML}$ in 2012 mainly from 10 biorefineries in the Canadian Prairies (western Canada) and another 4 in Ontario and Quebec (eastern Canada).

Under a multicriteria objective of minimizing production cost, reducing net GHG emissions, and to minimize soil degradation and other harmful environmental impacts, a systems perspective is required to link economic with environmental considerations-involving detailed analysis and modeling (i.e., life-cycle assessment) across biofuel supply chains. Such assessment-optimization-simulation quantitative methodologies can then more reliably assess if a biofuel provides real attainable benefits when displacing fossil fuels. Current systems-level research on biofuels (biodiesel and bioethanol) is directed to better assessing: the potential impacts of weather on feedstock supply and collection, more reliable forecasting of in-season feedstock yields, evaluating scenarios that explore climate trends and extremes on feedstock redistribution in relation to differential landscape suitability, assessing net-energy savings provided by coproducts and their industrial and commercial use within a range of potential industry and consumer markets, and assessing potential benefits of improved processing technology in reducing net GHG's. Amongst all these considerations, feedstock availability and cost remain the driving factors (i.e., $35-50 \%$ of production costs) having a major influence in determining where biorefineries are located as well as the rate at which the bioindustry expands. Existing models for biofuel supply-chain analysis, optimization, and simulation of future scenarios each have their various strengths and weaknesses in terms of flexibility/ease in enabling further model refinements and reliability testing. These models aim to explore process dynamics and to provide key insights to challenging questions, such as the following. (1) What are the key cost barriers in biofuel production and expansion? (2) What supply system/infrastructure improvements are needed and how to cope with such changes? (3) What are the technological advancements that will help to achieve government policy targets? (4) How to simultaneously maintain supply for multiple biorefineries, that is, systems of biorefineries and multicommodity supply-chains? Here, we focus attention on a selected set of 6 models representative of "state-of-the-art" biofuel supply chain analysis and provide key recommendations for improving supply-chain modeling both from a research (i.e., modeling) and their real-world multigenerational, multiproduct biorefinery supply perspective.

\section{Materials and Methods}

2.1. Data Sources. Available data compiled on oilseed and biodiesel production was obtained from market analysis reports and forecasts produced by Agriculture and Agri-Food Canada's Crop Market Information reporting [11] and the Global Agricultural Information Network (GAIN), United States Department of Agriculture (USDA) Foreign Agricultural Service. Information from technical reports and the published scientific literature was compiled for detailing the structure, attributes, and characteristics of the supply chain models (refer to references linked within Table 2).

Oilseed crop yield ( $\mathrm{kg} / \mathrm{ha}$, bushels/ha) and cropped area (ha) within Census of Agriculture Regions (CARs) (Statistics Canada, Field Crop Reporting Series) were used to generate the spatial distribution of oilseed production as the product of yield and area within each CAR polygon. This data is from all farms enumerated through the census and is weighted in order to produce unbiased level indicators which are representative of the population. These level indicators then undergo a validation process, based on subject matter analysis and consultation with provincial statisticians, before a final estimate is published. Coefficients of variation (CV) for specialty crops and small areas of major crops lie within $5 \%$ to $15 \%$.

Historical, interpolated climate data at the $10 \mathrm{~km}$, daily resolution has been validated across Canada and released to the public as a national agri-geomatics database by Agriculture and AgriFood Canada [12]. This high-resolution database was used to generate the frost kills spatial maps, assuming first frost kill occurs when air temperature is $<-2^{\circ} \mathrm{C}$.

\subsection{Overview of Supply-Chain Structure and Key Variables.} The biodiesel supply chain consists of 5 major segments: feedstock production, logistics, conversion, distribution, and end use (Figure 1). Feedstock production considers land use, land suitability, and crop area expansion and intensification. In Canada, lower tillage intensity and absence of liming reduce the energy required to grow oilseed crops; tillage systems applied are conventional till, minimum, and notill. The next segment involves logistical considerations linked with supply scheduling, namely, collection, pretreatment/drying, storage, and transportation. Here, for example, greenhouse gas (GHG) policies of carbon taxation, cap and trade, and carbon subsidies have the potential to significantly change not only scheduling of multiple feedstocks as part of segment 2 in the supply chain but also the selection of feedstocks (segment 1) and the design of biodiesel production facilities (segments 3, 4, and 5) [13]. Fertilizer and herbicide treatments for oilseeds are relatively uniform, specific to a 
TABLE 1: Harvested area, yield, and total production of the two main oilseeds grown in the Canadian Prairies (canola and flaxseed) for 2009/10 and forecasts for 2010/11 and 2011/12 cropping years (i.e., August-July) (reproduced from available 2011 oilseed and biodiesel production market analysis reports and forecasts $\left.{ }^{\dagger}\right)\left(\mathrm{k}\right.$ denotes $10^{3}, \mathrm{t}$ metric tonnes, and $\left.\mathrm{M} 10^{6}\right)$.

\begin{tabular}{|c|c|c|c|c|}
\hline Oilseed crop & Variable & 2009/10 actual & $2010 / 11$ forecast & $2011 / 12$ forecast \\
\hline \multirow{7}{*}{ Canola } & Area seeded (kt) & 6,556 & 6,806 & 7,500 \\
\hline & Area harvested (kt) & 6,105 & 6,514 & 7,368 \\
\hline & Yield (t/ha) & 2.03 & 1.82 & 1.75 \\
\hline & Production (kt) & 12.4 & 11.9 & 12.9 \\
\hline & Imports (kt) & 128 & 250 & 125 \\
\hline & Total supply (kt) & 14,206 & 14,239 & 14,125 \\
\hline & Average price $(\$ / t)$ & 426 & $540-580$ & $500-540$ \\
\hline \multirow{7}{*}{ Flaxseed } & Area seeded (kt) & 692 & 374 & 635 \\
\hline & Area harvested (kt) & 623 & 353 & 630 \\
\hline & Yield (t/ha) & 1.49 & 1.20 & 1.35 \\
\hline & Production (t) & 930 & 423 & 850 \\
\hline & Imports & 6 & 5 & 5 \\
\hline & Total supply & 1,165 & 717 & 905 \\
\hline & Average price $(\$ / \mathrm{t})$ & 424 & $520-550$ & $475-525$ \\
\hline \multirow{5}{*}{ Biodiesel } & Feedstock use (kt) & 160 & 175 & 475 \\
\hline & Production (ML) & 140 & 158 & 475 \\
\hline & Imports (ML) & 56 & 57 & 145 \\
\hline & Exports (ML) & 70 & 70 & 70 \\
\hline & $\begin{array}{c}\text { Number of facilities } \\
\text { (conventional blend } \\
\text { capacity) (ML) }\end{array}$ & $9(186)$ & $11(207)$ & $14(558)$ \\
\hline
\end{tabular}

\footnotetext{
${ }^{\dagger}$ http://www.agr.gc.ca/ under "Crops Market Information" and Global Agricultural Information Network (GAIN). Annual report for biofuels in Canada, 2011
} US Department of Agriculture (USDA) Foreign Agricultural Service.

given oilseed, due to the crop sequencing effect. This effect is the benefit of growing specific crops in the same field year after year arising from the maintenance of soil physical, chemical, and biological properties coupled with agronomic practices that promote nutrient and water-use efficiency and the control of diseases and pests.

A recent review of energy crops in rotation reveals that conventional crops can benefit from the introduction of oilseed crops for biodiesel production in the rotation [14]. Introduction of oilseeds into the rotation would impact segment 1 and may also include adjustments in harvesting methods. This situation is commonly considered in the case of bioethanol where reduced row space and higher cellulosic material content require harvesting technological adaptations, but less so for the case when oilseeds are introduced into the rotation in new areas and for land with varying topology. Diverse benefits of alternative oilseeds introduced into rotation, which are still able to produce high yields with high oil content, likely will relate to advantages in use of water and nutrients across the soil profile-especially in semiarid regions, such as the Canadian Prairies. With flax having a typically shallower rooting system than other oilseeds (e.g., safflower has a much deeper rooting), introducing other oilseeds in rotation could take advantage of accumulated soil nutrient and changes in soil-water content through the growing season.

Pre-treatment involved in segment 2 (supply logistics) considers preparation of biomaterial in relation to transport capacity and desired moisture content and densification level as well as performance limits for reactors and separators linked with conversion processes within segment 3 . Recent life-cycle assessment (LCA) for biodiesel energy balance shows an increase of $14 \%$ in energy gain for no-till compared to conventional tillage [15]. Energy inputs required to grow and convert canola to biodiesel are higher than for soybean, reflecting higher crop production inputs (i.e., fertilizer) and larger amounts of oil required for transesterification (conversion segment 3 ). Second-generation (2G) biorefinery design considerations are complex and involve multiple biochemical conversion processes-for example, $2 \mathrm{G}$ biodiesel combines gasification with syngas and Fischer-Tropsch synthesis to produce liquefied petroleum gas (LPG), naphtha, jet oil, and lubricants. Naphtha is important for the mining and chemical industry as it is used in diluents and solvents, respectively. It helps to meet viscosity and density requirements for pipeline transportation of liquid fuel material. Added hydrogenation to "green diesel" produces fuel blends with enhanced energy and GHG benefits compared with conventional biodiesel and to help meet end-user demands (segment 5) [16].

2.3. Optimization of Multi-criteria Objectives. The complexities involved in supply-chain modeling are optimized to meet various target objectives. Typically, total production cost over the chain is chosen as the main objective or utility function from which constraints are based. This is in part due to 
TABLE 2: Description and characteristics of four selected "state-of-the-art" models for optimizing biofuel production chains (i.e., biodiesel and/or ethanol) applicable to current decentralized configuration of multiple-biorefinery systems aimed at minimizing processing and production costs and enabling an enhanced level of strategic planning of future supply chain risks.

\begin{tabular}{|c|c|c|}
\hline Model source/country & Model formulation/benefits & Applied constraints/drawbacks \\
\hline $\begin{array}{l}\text { Parker et al. [4] } \\
\text { (2010, United States) }\end{array}$ & $\begin{array}{l}\text { (i) Mixed-integer } \mathrm{LP}^{\dagger} \\
\text { (ii) Maximizes annual revenue } \\
\text { (iii) Considers feedstock handling } \\
\text { efficiency/loss, conversion cost and } \\
\text { efficiency,and transportation costs } \\
\text { (iv) Simulates industry-wide fuel } \\
\text { production at fixed price, for generating } \\
\text { regional and/or state level exploring } \\
\text { supply-cost curve under different } \\
\text { feedstock mixes } \\
\text { (v) Model links with explicit feedstock } \\
\text { spatial distributions }\end{array}$ & $\begin{array}{l}\text { (i) Assumes value of all fuels have equal energy } \\
\text { content } \\
\text { (ii) Other than transport, does not consider many } \\
\text { aspects of supply logistics (i.e., pretreatment, } \\
\text { collection, storage) } \\
\text { (iii) Impact of associated supply risks due to } \\
\text { weather/climate-related variability and extremes } \\
\text { not taken into account } \\
\text { (iv) Intraannual (i.e., within-year) supply } \\
\text { dynamics not considered } \\
\text { (v) Net greenhouse gas benefits of biofuel } \\
\text { production from feedstock mixes not considered, } \\
\text { yet potentially has large effect on future crop } \\
\text { production feedstock/resource base }\end{array}$ \\
\hline
\end{tabular}

(i) Single-commodity, discrete (i.e., grid-based) noninteger LP

(ii) Minimizes annual production costs and system logistics (i.e., supply distance/time specific to each feedstock type)

(iii) Considers rural, semirural, and urban region types, with assumed

Dunnett et al. [5] (2008, United Kingdom)

"BioTrans"

Van Tilberg et al. [6]

(2005, European Union)

Huang et al. [7]

(2010, United States)

"industry of scale" cost reduction function

(iv) Considers pretreatment efficiency, transfer speed, and loading/unloading time for each feedstock supply logistics (v) Flexible framework for including range of processing tasks, logistical modes, coproducts, and regional policy constraints as dynamic extensions for real-world case study (i) Multicommodity, multistage, mixed-integer LP

(ii) Annual time step, minimising production costs and system logistics

(iii) Considers macroeconomic and technological projections in finding minimal cost allocations for supply chains

(iv) Detailed consideration of conversion processes (i) Assumes 10\% fractional availability of cropland as resource base

(ii) No link to explicit feedstock spatial distribution considers idealized crop spatial distributions as regional typologies: centralized and corner point

(iii) Lignocellulosic ethanol processing only currently simulated (i) Multistage, mixed integer LP

(ii) Annual time step, minimizes annual production costs and system logistics

(iii) Considers transboundary of feedstock supply and associated outsourcing penalty costs

(iv) Considers explicit feedstock distributions

(v) Considers fixed candidate refinery locations

(vi) Allows for increases in biorefinery capacity over time (i) Operates on a country aggregation level. Input and projections can be set at national level and costs and production quantities determined (ii) Requires each country to have a complete production and supply chain with one production or processing facility of each type, so difficult to apply at regional level

(iii) Impact of associated supply risks due to weather/climate-related variability and extremes not taken into account

(iv) Intraannual (i.e., within-year/in-season) supply dynamics not considered

(i) Developed for first application to lingocellulosic ethanol/biomass resources (ii) Landscape suitability/ratings specific to individual crops/feedstocks not currently considered, so only considers fixed set of candidate biorefinery locations

(iii) Impact of associated supply risks due to weather/climate-related variability and extremes not taken into account 
TABle 2: Continued.

\begin{tabular}{lll}
\hline Model source/country & Model formulation/benefits & Applied constraints/drawbacks \\
\hline & & (i) Relies on calibration of empirical relationships \\
& and other detailed look-up table (LUT) logistics \\
& (ii) Integrated biomass supply analysis & operation data, that is, primarily focused on the \\
and logistics model (IBSAL) & front end of the biofuels supply chain at the local \\
(iii) Simulates the flow of biomass & level \\
"IBSAL" & through collection, transport, storage, & (ii) No link to explicit feedstock spatial \\
Sokhansanj et al. [8] & and preprocessing considers costs, & distribution \\
energy, and net CO emissions & (iii) Enables sensitivity analysis of input data in \\
& multiobjectives considers weather & relation to empirically derived logistical \\
& impacts on supply-chain logistics & functions, but does not optimize, so lacks ability \\
& to explore more full supply-chain and & regional-scale scenarios \\
\hline
\end{tabular}

(i) Multicommodity, multistage, nonlinear LP

(ii) Implemented with a global parameter optimization scheme for enhanced robustness as model complexity increases (e.g., multiple chains, national-scale application)

Newlands et al. $[9,10] \quad$ (iii) Monthly time step, minimizes (2010, Canada) production costs and system logistics (iv) Considers multiple feedstocks/mix, multiple collection and single to multibiorefinery systems

(v) Model links with explicit feedstock distributions

(vi) Considers weather/climate impacts as part of supply cost scenarios

${ }^{\dagger}$ LP linear programming/optimization model.

the greater availability of supporting data for setting lookup tables (LUT) and other input data required for modeling against this objective. However, supply-chain models are expanding their efforts to explore scenarios around nearfeasible solutions against net- $\mathrm{CO}_{2}$ equivalent emission (i.e., net GHG's) objectives. Supply-chain models typically utilize idealized, grid-based coarse-grained spatial distribution data on feedstock distribution which offers considerable advantages for solving models using available linear and nonlinear programming (LP) optimization algorithms and exploring feasible and scenario-solution sets.

\section{Results}

3.1. Regional Perspective: Oilseed Production and the Canadian Prairies. Globally, soybean (Glycine L.) accounts for $60 \%$ of oilseed production, with cottonseed (Gossypium herbaceum L.) providing 10\%, closely behind napus canola (Brassica napus L.) and rapa canola (Brassica rapa L.) "rapeseed." Given the regional climate and agronomic factors related to favorable oilseed production, oilseed production in Canada is dominated by canola and flax (Linum usitatissimum L.) in the Canadian Prairies and by soybean in eastern Ontario and Quebec. The spatial distributions of major oilseed crop production (tonnes) for 2008 is shown in Figure 2, illustrating the overriding importance of land suitability, favourable climate, and other agronomic considerations required to grow oilseeds under Canadian conditions. Area polygons are based on Census of Agriculture Regions (CAR's) crop reporting sub-divisions for the Census of Agriculture conducted by Statistics Canada. The year 2008 was selected here to illustrate actual production for canola and flax during what was a particularly extreme climatic year-the Canadian Prairies experienced one of the worst droughts in decades, ravaging grain and oilseed crops, including hay and pasture. Northwestern Alberta experienced rainfall totals were $60 \mathrm{~mm}$ or $40 \%$ less than normal-its driest period in more than 40 years, with dryness becoming more extreme further southward. Daytime instability due to weaker weather frontal systems moving across the Prairies bringing warm, moist air from the Pacific reacted violently with the predominantly cooler air than normal residing over the Prairie region-producing intense storm and tornado activity. The summer of 2008 was the driest in 125 years in this growing region. The drought tolerance of both canola and flax is evident from attained production levels during such extreme conditions.

Canola (short for "Canadian oil") was developed by plant breeders in the Canadian Prairies (Saskatchewan/Manitoba) during the 1960-70s through conventional plant-breeding experiments [17]. Previously, the main impediment to growing canola/rapeseed varieties for food/edible oil production was due to its significant level of erucic and eicosenoic 


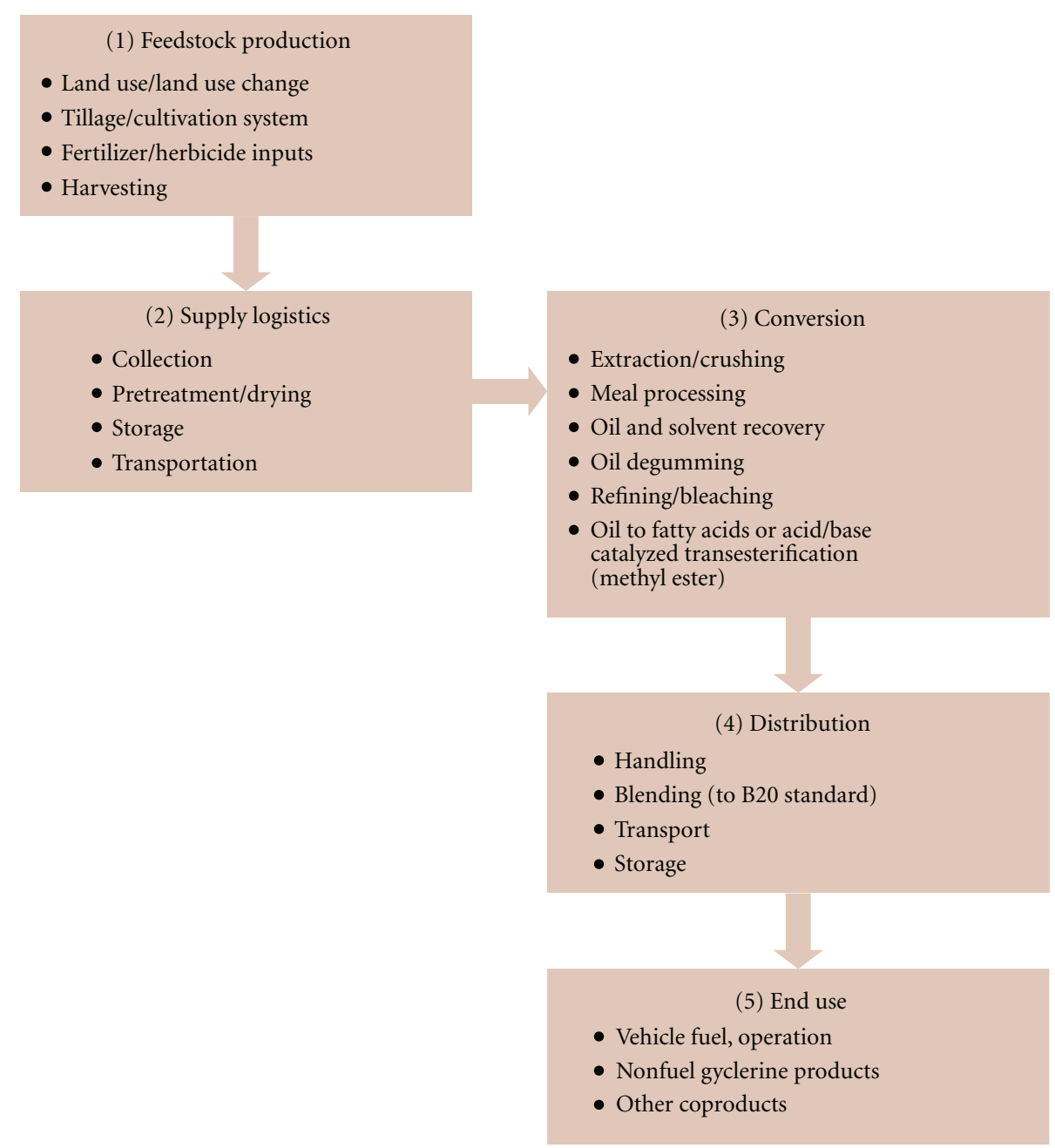

FIGURE 1: Generalization of the biodiesel supply chain with five major segments: feedstock production, logistics, conversion, distribution, and end use.

acids (nutritionally undesirable) and presence of sulphur compounds (glucosinolates) which impart sharp flavour characteristics (not favorable for wide human and livestock consumption). While this impediment was overcome by Canada and has made canola a major oilseed globally, there are other impediments facing the use of other oilseeds and the tradeoff in their use for food versus fuel. For example, one particular advantage of cottonseed oil that is increasingly being recognized is that it is more saturated than soybean oil and can be used to create oil blends or reduce the need for hydrogenation that creates transfatty acids. However, there are also increasing concerns in its use in the food industry given increasing evidence of its proteins causing allergic sensitivity and more serious reactions. The addition of cottonseed as the oil of choice (as when peanut was used) in manufacturing penicillin and vaccines may have contributed to major outbreaks of allergies and anaphylaxis in North America - and one reason why cottonseed although a more inexpensive oil, may be less favorable for food consumption as a cooking oil (i.e., than canola which has recognized health benefits as a source of unsaturated fat/vegetable oil) and better for biofuel or other bioindustrial production (e.g., detergents, soaps, fertilizers, inks, lubricants). Clearly, beneficial societal tradeoffs in the use of oilseeds for food or fuel production need to be better understood-and here the use of alternative nonfood oilseeds may have distinct advantages that Canadian oilseed producers and production biorefineries could exploit and expand upon.

Alternative oilseed crops have also been evaluated under the semiarid, short-growing season of the Canadian Prairies, such as juncea canola (Brassica juncea L.), Ethiopian mustard (Brassica carinata L.), oriental mustard (Brassica juncea L.), yellow mustard (Sinapis alba L.), and camelina (Camelina sativa L.) [18]. In particular, Camelina is considered more drought and heat tolerant and less susceptible to dominant pests. Camelina needs little water or nitrogen to flourish, and can be grown on marginal agricultural land and does not compete with food crops-so can be introduced as a rotation crop for wheat, increasing the health of the soil. Recent experimental studies in the Canadian Prairies on oilseeds indicate that crop emergence and growth were generally good for all oilseed crops, but soybean did not fully mature 


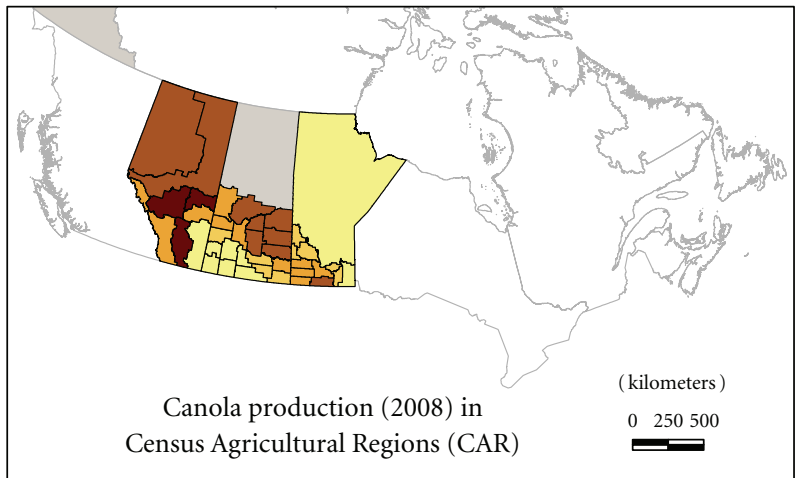

Canola production (tonne)

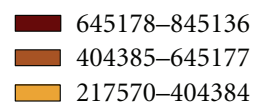

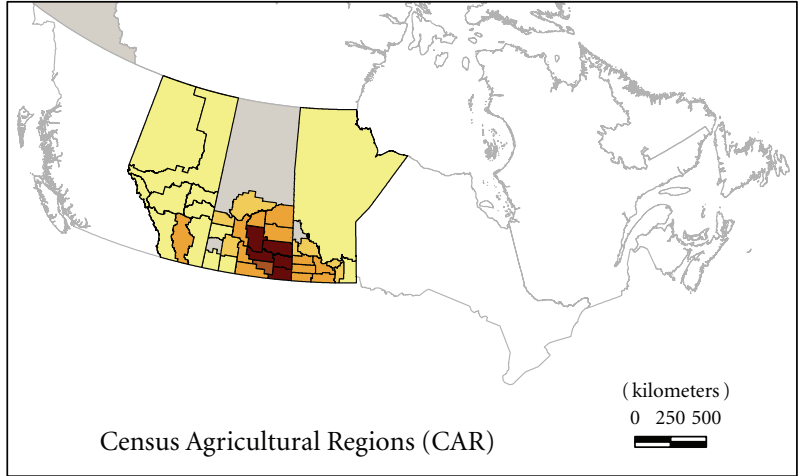

Flaxseed production (tonne)

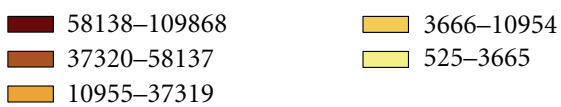

(b)

(a)

\section{$84445-217569$}

$4679-84444$

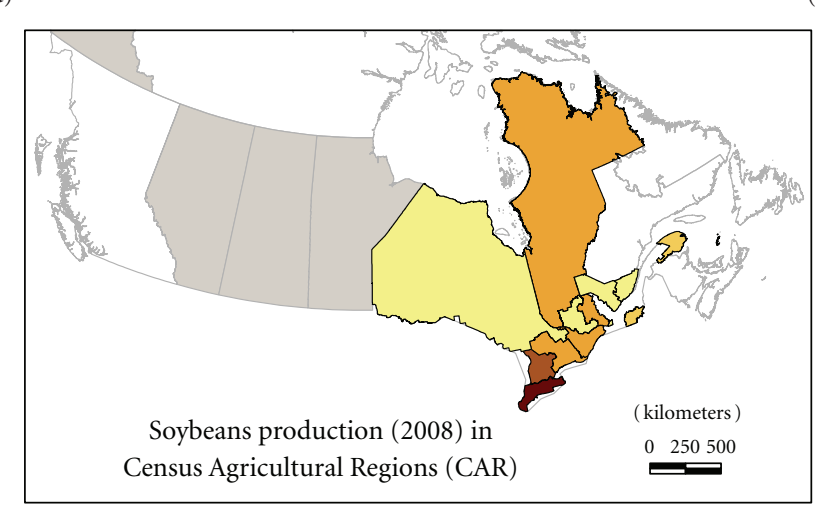

Soybeans production (tonne)

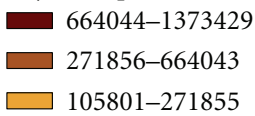

$\square 38501-105800$

$1290-38500$

(c)

FIGURE 2: Spatial distribution of production of major oilseed crops (tonnes) (i.e., canola and flaxseed in Western Canada and soybean in Eastern Canada) for 2008. Area polygons are based on Census of Agricultural Regions (CARs) crop reporting subdivisions of Statistics Canada.

at some locations. Considering yield and oil concentration, the alternative oilseed crops exhibiting the most potential for biodiesel feedstock were camelina, flax, rapa canola and oriental mustard, respectively. Oils of all crops were easily converted to biodiesel and quality analyses indicated that all crops would be suitable for biodiesel feedstock with the addition of antioxidants that are routinely utilized in biodiesel fuels. Reported findings from a multisite field study support that Ethiopian mustard has a comparable yet a longer duration to maturity (102-115 days) than other competing major biodiesel feedstock sources such as camelina and canola varieties (87-95 days). This indicates additional risk in growing alternative oilseeds such as Ethiopian mustard, if the impact of late growing-season climate variability on emergence, growth, and yield potential is not sufficiently understood and accounted for. The long-term viability of using dedicated industrial oilseed crops such as Ethiopian mustard (Brassica carinata L.) as a renewable source of jet fuel will, therefore, require a detailed understanding of key meteorological factors influencing the adaptation of this crop to the Canadian Prairies [19]. Companies like Agrisoma Inc. are continuing to develop elite carinata lines that increase the vigor of this crop, increase its drought and heat tolerance (i.e., adaptability), and increase its resistance to Blackleg. Second-generation lines currently being developed aim to achieve a $10-20 \%$ increase in yield and significant increases in seed oil content, including enhancing its oil quality and crop productivity traits.

3.2. Current and Forecasted Biodiesel Production. For 20112012, seeded area for canola is forecast to increase $10 \%$ as a new record due to strong prices and high-expected yields 
(see Table 1). In contrast, flaxseed oil-seeded area is forecast to rise by $70 \%$, but domestic use to fall by $36 \%$ due to high prices, in part due to a forecasted decline in area in summer fallow that considers that areas too wet to be seeded in 2010 will be seeded in 2011 [11]. However, this also assumes normal precipitation and crop quality, but yield forecasts are likely also particularly sensitive to spring moisture conditions. Moving from the feedstock to the biodiesel production perspective, most of the current forecasted increase in biodiesel production is based on potential production from rendered animal fats at $250 \mathrm{ML}$. Higher prices for oilseeds likely will hinder Canada's ability to supply the necessary supply feedstock to meet biodiesel targets. The Federal Government's biofuel strategy program is more geared to bioethanol reducing the ability to address limiting factors for biodiesel market growth-especially where sensitive trade-offs via subsidies between oil from crushing plants directed for biodiesel production versus human consumption are involved.

The mix of feedstock that can most reliably supply the $2 \%$ biodiesel federal mandate is a major outstanding question. Rendered oils (yellow grease), animal fats (tallow), and palm oil (imported into Canada) are much cheaper oils that are priced at feed and industrial-use levels that strongly compete with use of canola for biodiesel. Also, canola (produced mainly in the Prairies, western Canada) and soybean (produced in Ontario, eastern Canada) are both high-priced food oils subject to international market prices and pressures. As their demand in food and biodiesel continues to rise (based on current forecasts), their price is likely to also increase. In contrast to canola soon to contribute over $50 \%$ of Canada's biodiesel, roughly $54 \%$ of biodiesel production in the United States is currently produced from soybean oil. Canada's and the United States' dominant use of canola, and soybean is related to the advantages of using higher-priced oilseeds in terms of quantity and quality of free glycerol or glycerin coproduct (roughly $10 \%$ of final product) as well as anticipated technological improvements in coproduct production processes.

3.3. High Spatial Variability and Volatility in Supply Risks. Future land-use simulations for the Canadian Prairies indicate an increase in the intensiveness of agricultural production of spring grains and oilseeds, and increased conversion of pasture acreage [20]. Such land conversion is predicted to occur heterogeneously, with CARs in Southern Saskatchewan losing less than $5 \%$ of their pasture acres, to Northcentral Alberta, where CARs are predicted to lose 20\%. Not surprisingly, largest losses in pasture (i.e., the highest quality land available that is being used for growing hay and livestock pasture) and highest rates of land conversion are predicted for areas with low current land-use shares for intensive crops (i.e., wheat, canola, and flax). As more land converts for growing canola, for example, early frosts and wetter conditions can prove unfavorable at harvest as it can damage the seed so that it is unsuitable for human consumption-such that roughly $2-10 \%$ in any year may be currently available for biodiesel, due to such unfavorable conditions). Figure 3 shows the spatial distribution of early season (i.e., first) frost kill temperatures $\left(T<-2^{\circ} \mathrm{C}\right)$ across the Canadian Prairies at a spatial resolution of $10 \mathrm{~km}$, for selected years. Frost kill is an indicator of higher probability in crop frost damage. These historical frost patterns show large interannual variability in frost kill and high unpredictability in predicting crop damage in any one year. As more land area is used to grow canola, given its high oil content, its storage needs to be kept dry and cool, which presents additional logistical challenges as oilseed crop area expansion and area intensification increase, alongside the demand for canola for both food and biodiesel use. Strategic policy biofuel initiatives that incorporate considerations of differential land suitability and its spatial heterogeneity in relation to conversion risks will likely be the ones that provide the greatest enhancement of supplychain reliability, by reducing risk volatility, and increase the effectiveness of use of land for growing oilseeds used in both food and biodiesel supply-chain production. This is because allocating too much land for only one crop, such as canola, introduces known risks associated with monoculture-such as an increased potential risk of disease when occupying the full rotation and reduced soil fertility. High levels of climate and crop production spatial variability adds considerable complexity to modeling biodiesel supply-chain production-and requires an enhanced ability to forecast crop yield in-season. Such forecasting methodologies must consider potential impacts and risks of regional climate changes and extreme events for mapping changing land suitability (i.e., already spatially heterogeneous) and for forecasting different levels of supply risk volatility associated with different feedstock mixtures and their supply radii for regional biorefinery/systems. Increasingly, the use of remote-sensing information to provide rapid, broad-based spatial coverages for identifying crop distribution and status through phenological development stages (i.e., in-season) is being integrated within agricultural crop forecasting system operational frameworks.

3.4. Supply-Chain Models: Benefits and Drawbacks. Six stateof-the-art models for optimizing supply chains (e.g., for biodiesel production) are profiled in Table 2 . These models are currently being employed for exploring decentralized configurations of multiple-biorefinery systems aimed at minimizing processing and production costs [21-24]. While the level of detail in their input data, objective criteria, and spatial and temporal assumptions of supply chain dynamics differ, their structures all encompass the major segments of the supply-chain (as per Figure 1). Also, they collectively target the common modeling goal of enabling an enhanced level of strategic planning of future supply-chain risks. Assumed level of detail between the models, in part, reflects differing extents of data availability, whether they maintain linear assumptions on variables or not, accuracy of the core optimization numerical algorithm employed, application spatial scale (regional, national, transboundary), and desired level of flexibility for scenario-based simulation and the degree that they are designed for use by a range of stakeholders. For example, BioTrans (EU) [6] is particularly well designed for trans-boundary application, and IBSAL (US) [22] is well designed for supply logistics, and both 


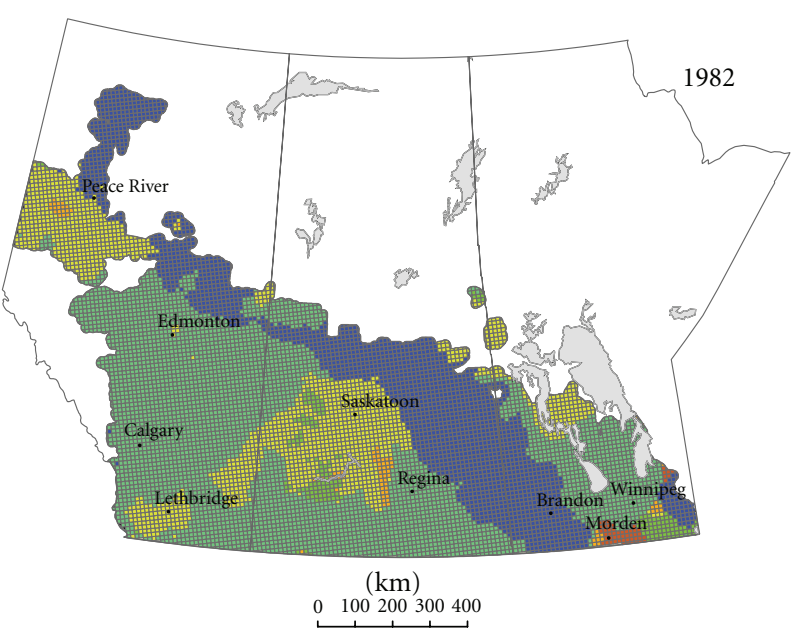

(a)

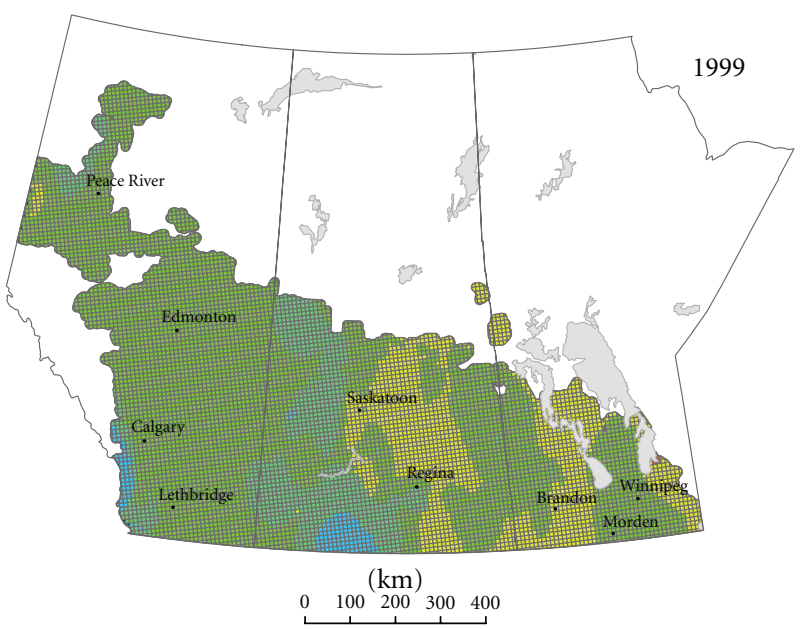

The first frost day

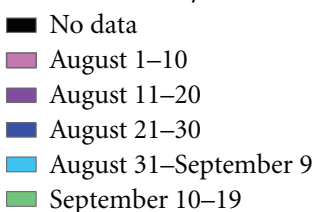

$$
\begin{aligned}
& \square \text { September 20-29 } \\
& \square \text { September 30-October } 9 \\
& \square \text { October 9-19 } \\
& \text { October } 20-29 \\
& \square \text { October 30-November } 14
\end{aligned}
$$

(c)

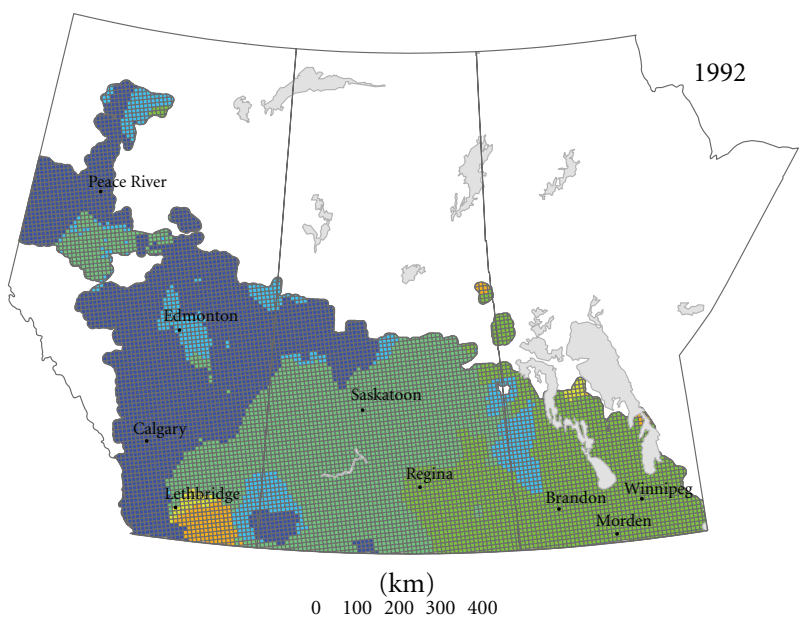

(b)

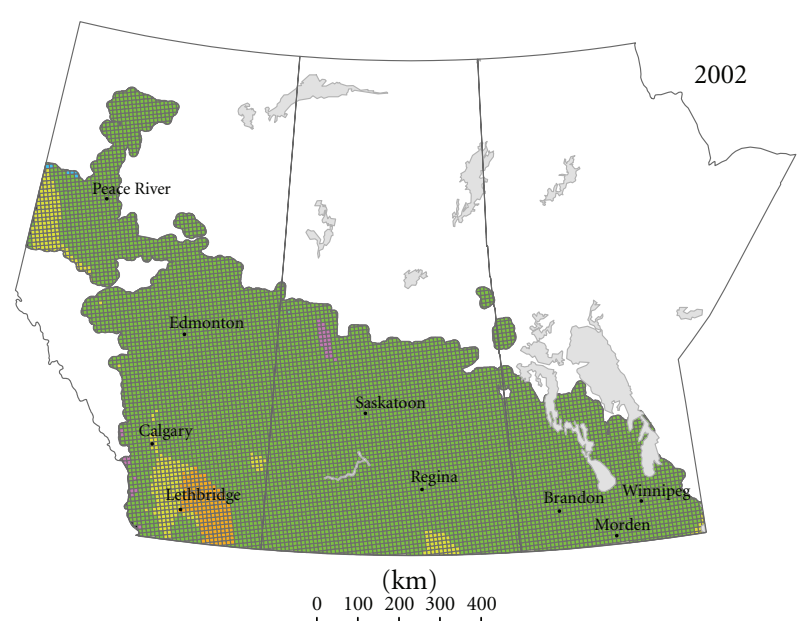

The first frost day

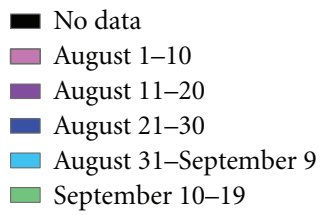

$\square$ September 20-29

$\square$ September 30-October 9

$\square$ October 9-19

- October 20-29

- October 30-November 14

(d)

FIGURE 3: Spatial distribution of early-season (i.e., first) frost kill temperatures $\left(T<-2^{\circ} \mathrm{C}\right)$ across the Canadian Prairies at a spatial resolution of $10 \mathrm{~km}$, for selected years (frost kill is an indicator of higher probability in crop frost damage). These historical frost patterns show large interannual variability in frost kill and high unpredictability in predicting crop damage in any one year.

have considerable flexibility and ease of use by stakeholders. Other models $[4,5,7-10]$ emphasize supply network configuration design and are primarily research driven for exploring science-based or policy-setting scenarios. Overall, a summary of their characteristics reveals a common thread, whereby each model tends to focus on certain stages of the supply chain or central aspect to explore at greater detail building in data or concepts from more empirical sourcesthis identifies that there is a high potential for beneficial integration of improved segment design between the models. Moreover, substantial gains are likely if modelers were to increase the level of data and contextual-based information sharing. There are clear differences between the models in terms of their use of spatial information of feedstock supply (i.e., idealized, grid based, resolution scale). The evolution in the development of these models is clear: from considering single to mixes of different feedstocks, from cost only to multiobjectives, and from changing level of detail to best address changing scale of application (regional, national, trans-boundary). Nonetheless, there are several key areas where all the models require extension to better address data and model-based variability; namely, (1) changing spatial 
considerations (e.g., land-use and suitability for different feedstocks) (2) changing temporal dynamics of supply and risk due to climate-related impacts on transportation networks (road, rail, pipeline), market international pricing volatility, changes in policy targets and subsidy regimes as well as technological change associated with multi-generational biorefinery systems engineering advancements.

\section{Discussion}

Without a sufficient level of spatial detail being considered, it may be difficult for supply-chain models to capture important spatial trends related to the impact of pests, climate extremes on crop productivity, or to obtain reliable estimates of feedstock supply and various mixes required by biorefinery systems. Current supply-chain models need to better incorporate geospatial information to enable more resolved ability to explore the effects of land use change. Important spatial effects that need to be considered include the increasing encroachment of crops on more marginal lands, as well as, crop intensification dependent on land suitability, climate fluctuations and its regionally-varying impact. With spatial enhancement, these models can be used to provide key statistical and scenario-based insights on system adaptation in response to favourable meteorological conditions for growing new oilseed alternatives for emerging markets such as jet fuel, lubricants, plastics, and other biobased materials. How alternative oilseeds introduced into the rotation can make more use of available soil nutrients and retained water in relation to their rooting depth and how further intensification could lead to unfavourable consequences currently provided by crop sequencing are important questions that would assist in designing more realistic supplychain scenarios for biodiesel in the Canadian Prairies. A review of a representative set of state-of-the-art supply-chain models reveals several key areas where all the models require extension to better address data and model-based variability; namely, (1) changing spatial considerations (e.g., land-use and suitability for different feedstocks) and (2) changing temporal dynamics of supply and risk due to climate-related impacts on transportation networks (road, rail, pipeline), market international pricing volatility, and changes in policy targets and subsidy regimes as well as technological change associated with multi-generational biorefinery systems engineering advancements. Supply-chain models must continue to improve the ability to involve stochastic variables and multiobjective functions and constraints (cost, net GHG's, biodiversity, nutrient and water-efficiency, risk volatility) and to enable more flexible adjustment of model structure to become more user friendly (i.e., more transparent, visualization of model structure). This will, in turn, enable a broader base of input and involvement from a wide range of stakeholders to accelerate their development. For example, the same model, if designed with sufficient flexibility, could be applied to explore consequences and risks across a hierarchy of spatial applications (local, regional, trans-boundary). This would, in turn, aid in attaining more consistent and reliable information to examine sensitivity and evaluate uncertainty of predictions and forecasts across different spatiotemporal scales and application contexts.

\section{Acknowledgments}

This paper was funded by the Canadian Federal Government via Agriculture and Agri-Food Canada's (AAFC's) Sustainable Agriculture Environmental Systems (SAGES) program. Historical crop yield data at the Consolidated Statistical Division (CSD) level was derived from Statistic Canada's Field Crop Reporting Series provided as an input to an AAFC research project (PI: Ted Huffman) on crop production and environmental modeling. The authors thank Mr. Zhirong Yang (AESB/AAFC) for assistance in generating spatial maps of frost kill and oilseed crop production across the Canadian Prairies.

\section{References}

[1] P. Stelios and G. Mercier, "Renewable energy in Canada," Tech. Rep., Renewable Energy Working Party (REWP) of the International Energy Agency (IEA), Natural Resources Canada, Ottawa, Canada, 2002.

[2] J. Hill, E. Nelson, D. Tilman, S. Polasky, and D. Tiffany, "Environmental, economic, and energetic costs and benefits of biodiesel and ethanol biofuels," Proceedings of the National Academy of Sciences of the United States of America, vol. 103, no. 30, pp. 11206-11210, 2006.

[3] Environment Canada (EC), "Greenhouse gas sinks and sources in Canada, 1990-2009," National Inventory Report, The Canadian Government's Submission to the United Nations Framework Convention on Climate Change (UNFCC), 2011, http://www.ec.gc.ca/ges-ghg/.

[4] N. Parker, P. Tittmann, Q. Hart et al., "Development of a biorefinery optimized biofuel supply curve for the Western United States," Biomass and Bioenergy, vol. 34, no. 11, pp. 1597-1607, 2010.

[5] A. J. Dunnett, C. S. Adjiman, and N. Shah, "A spatially explicit whole-system model of the lignocellulosic bioethanol supply chain: an assessment of decentralised processing potential," Biotechnology for Biofuels, vol. 1, p. 13, 2008.

[6] X. van Tilberg, R. Egging, and M. Londo, Biofuel Production Chains: Background Document for Modeling the EU Biofuel Market Using the BioTrans Model, Energy Research Centre of the Netherlands, Policy Studies Unit, Petten, The Netherlands, 2005.

[7] Y. Huang, C. W. Chen, and Y. Fan, "Multistage optimization of the supply chains of biofuels," Transportation Research E, vol. 46, no. 6, pp. 820-830, 2010.

[8] S. Sokhansanj, A. Turhollow, and E. Wilkerson, "Development of the Integrated Biomass Supply Analysis and Modeling Tool (IBSAL)," Tech. Rep. ORNL/TM-2006/57, United States Department of Energy, Oak Ridge National Laboratory (ORNL), Environmental Sciences Division/Bioenergy Resources and Engineering Systems Group, 2008.

[9] N. K. Newlands, J. Pinter, and B. McConkey, "Supply-chain optimization modeling of lingo-cellulosic ethanol within Canada: scoping document and model-development," Tech. Rep., Technical Report to the Canadian Federal Program of Energy Research and Development (PERD) and Canadian Biomass Innovation Network (CBIN), 2008, Agriculture and Agri-Food Canada (AAFC).

[10] N. K. Newlands and L. Townley-Smith, Bayesian Network Model of Energy Crop Yield, Computational Intelligence, ACTA Press, Calgary, Canada, 2010. 
[11] Statistics Canada, “Cereals and oilseeds review," Tech. Rep. 22007-X, Government of Canada, Ottawa, Canada, 2011.

[12] N. K. Newlands, A. Davidson, H. Hill, and A. Howard, "Comparison of three methods for spatially interpolating daily precipitation and temperature across Canada," Environmetrics, vol. 22, no. 2, pp. 205-223, 2010.

[13] R. D. Elms and M. M. El-Halwagi, "The effect of greenhouse gas policy on the design and scheduling of biodiesel plants with multiple feedstocks," Clean Technologies and Environmental Policy, vol. 12, no. 5, pp. 547-560, 2010.

[14] W. Zegada-Lizarazu and A. Monti, "Energy crops in rotation. A review," Biomass and Bioenergy, vol. 35, no. 1, pp. 12-25, 2011.

[15] E. G. Smith, H. H. Janzen, and N. K. Newlands, "Energy balances of biodiesel production from soybean and canola in Canada," Canadian Journal of Plant Science, vol. 87, no. 4, pp. 793-801, 2007.

[16] A. C. Kokossis and A. Yang, "On the use of systems technologies and a systematic approach for the synthesis and the design of future biorefineries," Computers and Chemical Engineering, vol. 34, no. 9, pp. 1397-1405, 2010.

[17] L. Casseus, "Canola: a Canadian success story," Tech. Rep. 96-325-X, Government of Canada/Statistics Canada, Ottawa, Canada, 2009, Canadian Agriculture at a Glance.

[18] R. E. Blackshaw, E. N. Johnson, Y. T. Gan et al., "Alternative oilseed crops for biodiesel feedstock on the Canadian Prairies," Canadian Journal of Plant Science, vol. 91, no. 5, pp. 889-896, 2011.

[19] A. Getinet, G. Rakow, and R. K. Downey, "Agronomic performance and seed quality of Ethiopian mustard in Saskatchewan," Canadian Journal of Plant Science, vol. 76, no. 3, pp. 387-392, 1996.

[20] B. S. Rashford, C. T. Bastian, and J. G. Cole, "Agricultural landuse change in Prairie Canada: implications for wetland and waterfowl habitat conservation," Canadian Journal of Agricultural Economics, vol. 59, no. 2, pp. 185-205, 2011.

[21] D. M. Yazan, A. Claudio Garavelli, A. Messeni Petruzzelli, and V. Albino, "The effect of spatial variables on the economic and environmental performance of bioenergy production chains," International Journal of Production Economics, vol. 131, no. 1, pp. 224-233, 2011.

[22] B. Velazquez-Marti and E. Fernandez-Gonzalez, "Mathematical algorithms to locate factories to transform biomass in bioenergy focused on logistic network construction," Renewable Energy, vol. 35, no. 9, pp. 2136-2142, 2010.

[23] J. Gan and C. T. Smith, "Optimal plant size and feedstock supply radius: a modeling approach to minimize bioenergy production costs," Biomass and Bioenergy, vol. 35, no. 8, pp. 3350-3359, 2011.

[24] U. D. Tursen, S. Kang, H. Onal, Y. Ouyang, and J. Scheffran, "Optimal biorefinery locations and transportation network for the future biofuels industry in Illinois," Resource Management and Policy, vol. 33, no. 3, pp. 151-173, 2010. 


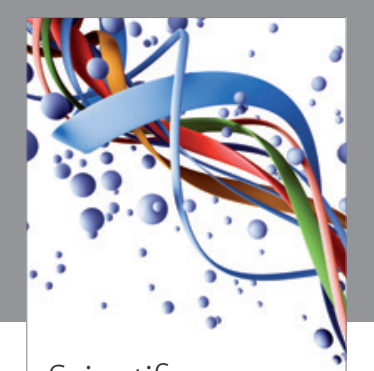

Scientifica
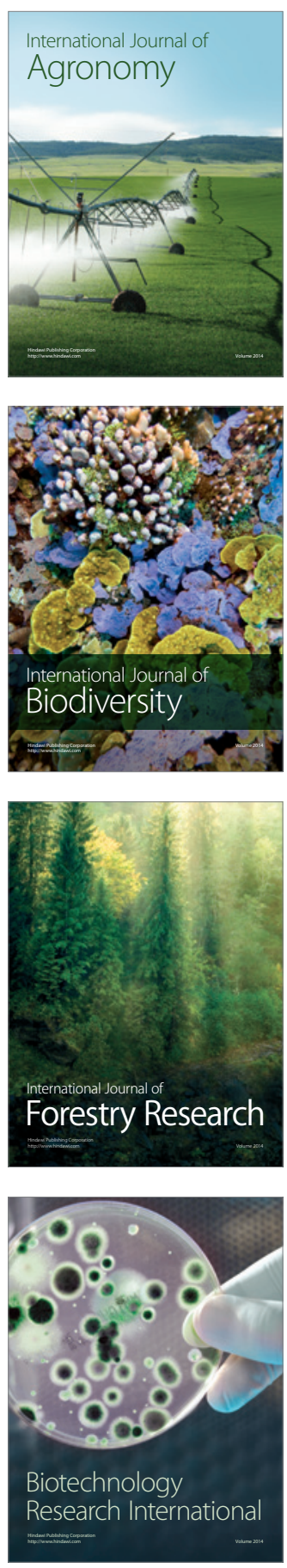
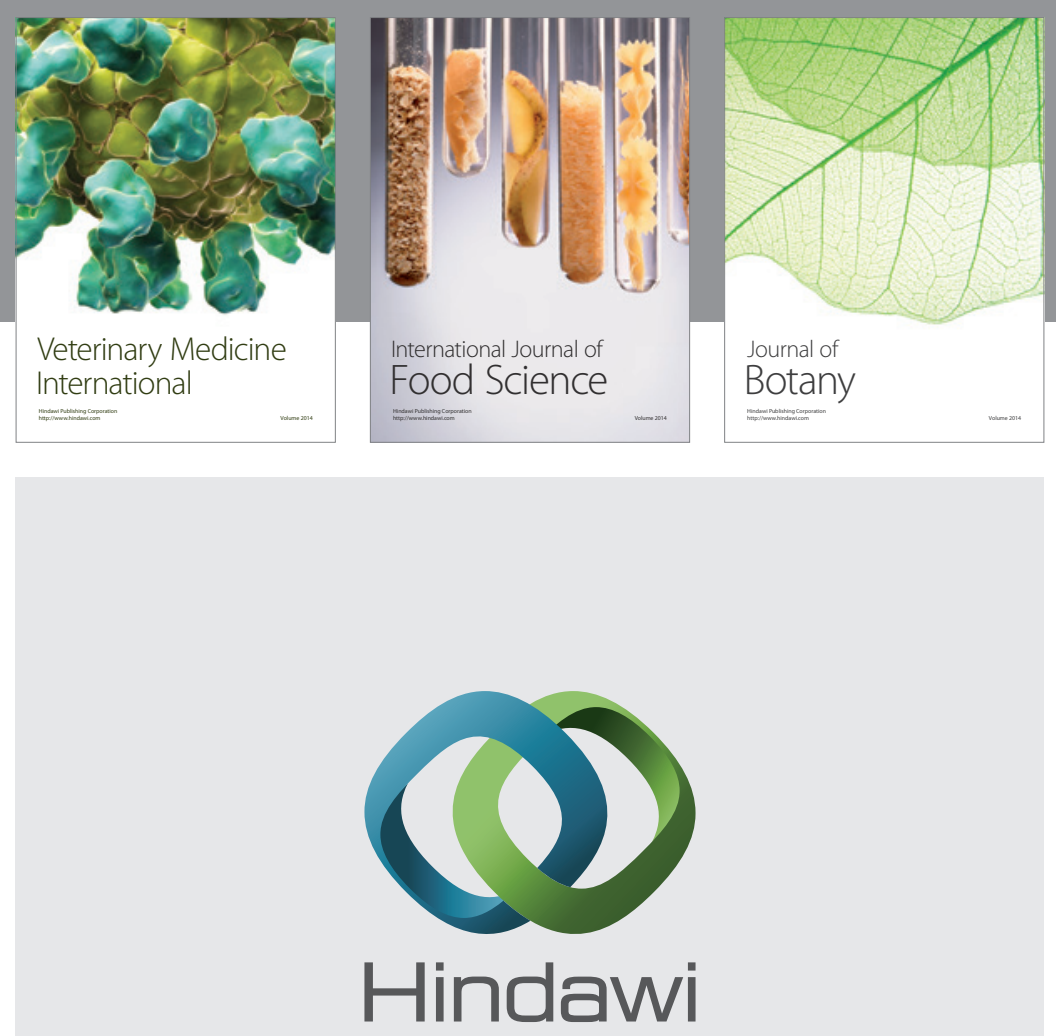

Submit your manuscripts at

http://www.hindawi.com
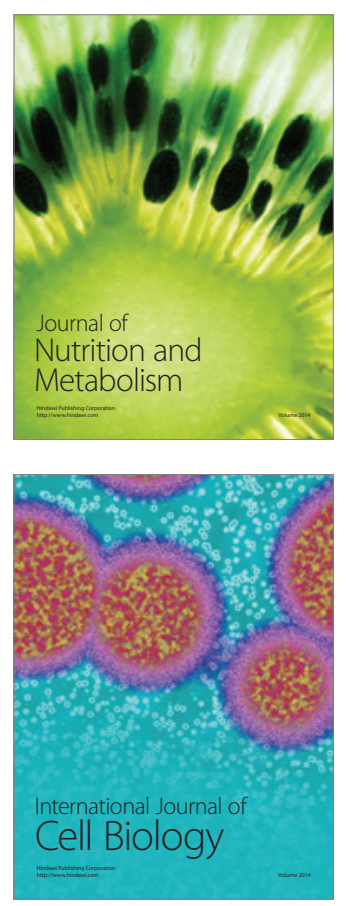
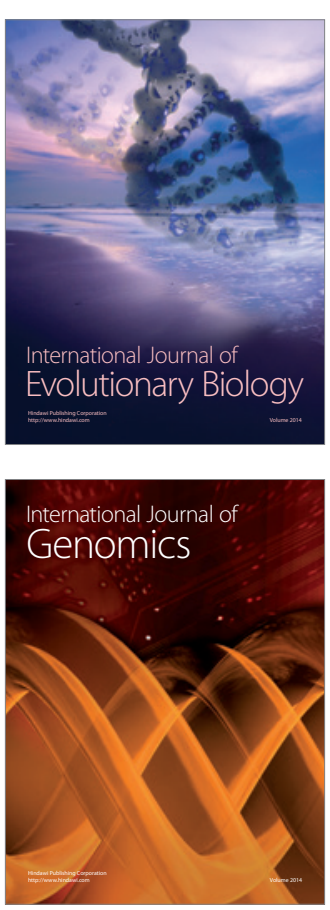
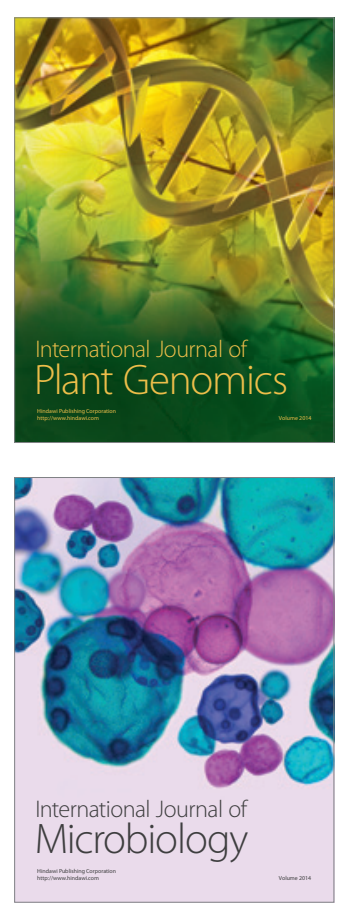

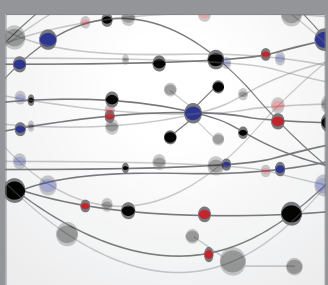

The Scientific World Journal
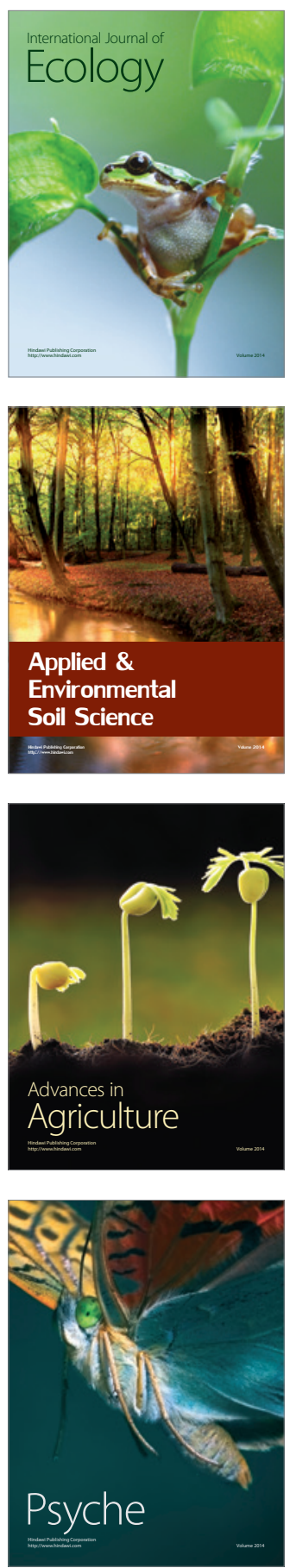